\title{
Antipsychotic-Induced Hyperprolactinemia
}

\author{
Jolene R. Bostwick, Pharm.D., Sally K. Guthrie, Pharm.D., FCCP, and \\ Vicki L. Ellingrod, Pharm.D., FCCP
}

Use of antipsychotic agents has been associated with hyperprolactinemia, or elevated prolactin levels; this hormonal abnormality can interfere with the functioning of reproductive, endocrine, and metabolic systems. As antipsychotic agents are increasingly used for both United States Food and Drug Administration-approved and nonapproved indications, many individuals are at risk for developing antipsychotic-induced hyperprolactinemia. First-generation antipsychotics pose the greatest risk of causing this adverse effect; however, second-generation antipsychotics, particularly risperidone and paliperidone, also often increase prolactin secretion. Hyperprolactinemia has short- and long-term consequences that can seriously affect quality of life: menstrual disturbances, galactorrhea, sexual dysfunction, gynecomastia, infertility, decreased bone mineral density, and breast cancer. Although many of these are definitively connected to elevated prolactin levels, some, such as breast cancer, require further study. Both clinicians and patients should be aware of hyperprolactinemia-associated effects. To prevent or alleviate the condition, tailoring an antipsychotic drug regimen to each individual patient is essential. In addition, the risk of hyperprolactinemia can be minimized by using the lowest effective dose of the antipsychotic agent. If the effects of prolactin are evident, the drug can be changed to another agent that is less likely to affect prolactin levels; alternatively, a dopamine agonist may be added, although this may compromise antipsychotic efficacy. Additional research is needed to clarify the appropriate level of monitoring, the long-term effects, and the optimal treatment of antipsychotic-induced hyperprolactinemia. Key Words: hyperprolactinemia, prolactin, antipsychotics, schizophrenia, osteoporosis, breast cancer, amenorrhea, sexual dysfunction.

(Pharmacotherapy 2008;29(1):64-73)

\section{OUTLINE}

Prolactin

Physiologic Effects of Hyperprolactinemia

Antipsychotic-Induced Hyperprolactinemia

Prevalence

Consequences

Antipsychotic Drug Selection and Management of the Effects of Hyperprolactinemia

Conclusion

From the Department of Clinical, Social, and Administrative Sciences, University of Michigan College of Pharmacy, Ann Arbor, Michigan (all authors).

Address reprint requests to Jolene R. Bostwick, Pharm.D., BCPS, Department of Clinical, Social, and Administrative Sciences, University of Michigan College of Pharmacy, 1500 East Medical Center Drive, SPC 0118, Ann Arbor, MI 48109.
Use of antipsychotic agents has been associated with hyperprolactinemia, or elevated prolactin levels. Hyperprolactinemia is more than an abnormal laboratory value; elevated prolactin levels can interfere with the functioning of reproductive, endocrine, and metabolic systems. When first-generation antipsychotics were the only treatment available for psychosis, hyperprolactinemia from use of these agents was recognized but often ignored. All of the firstgeneration antipsychotics caused hyperprolactinemia, and elevated prolactin levels were generally accepted as both inevitable and preferable to untreated psychosis. With the advent of atypical or second-generation antipsychotics, clinical 
monitoring and identification of the consequences of hyperprolactinemia have received greater recognition because these agents can offer a differential profile of adverse effects and some of the newer agents cause little to no elevation of prolactin levels. Recent research has provided a more comprehensive understanding of the many functions of prolactin that result in the multifactorial effects of hyperprolactinemia.

\section{Prolactin}

Prolactin is a polypeptide hormone that contains 199 amino acids and is categorized as part of the growth hormone family. ${ }^{1}$ It is secreted primarily by lactotroph cells located in the anterior pituitary. Prolactin also is produced in other locations such as adipose cells in subcutaneous, breast, and visceral tissues. Although the best known actions of prolactin relate to reproduction, pregnancy, and lactation, the hormone appears to be involved in many more functions than previously thought. ${ }^{2}$ Prolactin binds to specific prolactin receptors that belong to the class I cytokine receptor family and are present in organs such as the pancreas, liver, uterus, and prostate. ${ }^{3}$ Binding at the prolactin receptor results in activation of a variety of signaling pathways that alter the transcription of genes causing tissue changes. ${ }^{1,2}$

Secretion of prolactin is pulsatile, with peaks and troughs that follow a circadian cycle. Peak secretion occurs nightly, approximately 4 hours after sleep onset, and the nadir occurs in the morning, approximately 6 hours after waking. In addition to circadian peaks, prolactin levels are transiently elevated by meals, stress, and sexual activity. Regulation is complex, with serotonin (through $5-\mathrm{HT}_{1 \mathrm{~A}}$ and $5-\mathrm{HT}_{2}$ receptors) causing stimulation of prolactin release and estrogen causing increased production of prolactin. However, the major regulation of pituitary prolactin secretion is largely inhibitory. ${ }^{4}$ Dopamine, which is released by tuberoinfundibular neurons, normally acts at $\mathrm{D}_{2}$ receptors on lactotropes to tonically inhibit prolactin secretion and maintain physiologically normal prolactin levels in the blood. The Taql A polymorphism of the $\mathrm{D}_{2}$-receptor gene may play a role in the strength of dopamine-mediated inhibition of prolactin secretion. Carriers of the less frequent Al allele have a lower density of $\mathrm{D}_{2}$ receptors in the striatum, which can lead to a dopamine deficiency through higher $D_{2}$ occupancy, increasing the risk for antipsychoticinduced hyperprolactinemia. ${ }^{5-7}$ This may be particularly important for female patients with the Al allele, who appear to be at an increased risk for developing antipsychotic-induced hyperprolactinemia. ${ }^{5,8}$

Because of the complex regulation of prolactin release, a variety of drugs have been associated with hyperprolactinemia, such as antidepressants (triand tetracyclic antidepressants, monoamine oxidase inhibitors, serotonin-specific reuptake inhibitors), gastrointestinal drugs (metoclopramide, domperidone), antihypertensives (methyldopa, verapamil, reserpine), some serotonergic drugs, antiandrogens, estrogens, opiates, and cocaine.9, 10 Patients taking these drugs, particularly if used in combination with antipsychotic agents, may be at an increased risk for drug-induced hyperprolactinemia.

\section{Physiologic Effects of Hyperprolactinemia}

Any individual taking a drug that blocks the inhibition of prolactin secretion is at risk for the development of hyperprolactinemia; however, specific populations such as children, adolescents, premenopausal women, and women in the perinatal period are at higher risk. ${ }^{1}$ During pregnancy, the secretion of prolactin levels is elevated 10-20 times the nonpregnant value, resulting in breast enlargement and milk production, as well as decreases in libido and fertility. Prolactin also affects actions of other hormones and enzymes in a variety of tissues. For instance, in hepatocytes, prolactin activates a cotransporting peptide for sodium-taurocholate; in $\mathrm{T}$ lymphocytes, prolactin promotes production of interferon-regulatory factor 1 ; and in reproductive tissue, it induces transcription of the estrogen receptor and $3 \beta$-hydroxysteroid dehydrogenase. ${ }^{3}$ Prolactin not only is produced within adipose tissues but also may have a regulatory function in the tissue, although that exact function has not yet been determined.

Since prolactin has some of its strongest effects on the reproductive system, it is not surprising that a supraphysiologic elevation of prolactin level should affect the reproductive organs. Drug-induced hyperprolactinemia, resulting in elevations of prolactin level 2-4 times the upper limit of the normal range of $15-25 \mu \mathrm{g} / \mathrm{L}$ in men and women, causes significant effects on the reproductive system. Elevated prolactin levels can affect sex hormone dysfunction by inhibiting the release of hypothalamic gonadotropinreleasing hormone. ${ }^{11}$ Once gonadotropinreleasing hormone is inhibited, release of luteinizing hormone and follicle-stimulating 
hormone from the pituitary is also inhibited. The inhibition of luteinizing hormone and follicle-stimulating hormone by elevated prolactin levels occurs in both men and women, resulting in reduced testosterone and estrogen production that can lead to widespread consequences. ${ }^{12}$

Short-term concerns associated with hyperprolactinemia include menstrual disturbances, galactorrhea, sexual dysfunction, and infertility in women, as well as sexual dysfunction and gynecomastia in men. ${ }^{1,13}$ Galactorrhea can occur in both sexes, but it is more common in women and may occur in up to $57 \%$ of those experiencing elevated prolactin levels. ${ }^{14,15}$ Gynecomastia, however, is fairly uncommon. ${ }^{11}$

Prolonged hyperprolactinemia through estrogen deficiency in women and testosterone deficiency in men may result in decreased bone mineral density (BMD) in both men and women. ${ }^{13,15-17}$ This can be especially concerning in younger patients treated with prolactinelevating drugs who have not yet achieved peak BMD. ${ }^{18}$

Finally, another potential long-term effect of hyperprolactinemia is breast cancer in women. ${ }^{13}$ This longstanding debate was spurred by the finding that prolactin plays a key role in the development of mammary tumors in mice and rats. ${ }^{19}$ In the 1970s, some clinicians recommended against the use of drugs that can lead to hyperprolactinemia in patients with this disease or if breast cancer is suspected. ${ }^{20,21}$ The debate of the effect of prolactin on breast cancer in humans is being revisited.

\section{Antipsychotic-Induced Hyperprolactinemia}

\section{Prevalence}

The prevalence of hyperprolactinemia secondary to the use of an individual antipsychotic is roughly equated to the potency of its ability to block $\mathrm{D}_{2}$ receptors. The first-generation antipsychotics are generally associated with greater risks of prolactin level elevation compared with second-generation antipsychotics, with the exception of risperidone and paliperidone. ${ }^{12,22,23}$

When the second-generation antipsychotics were initially marketed, there was widespread hope that many of the adverse effects that had been problematic with first-generation antipsychotics, such as anticholinergic effects, shortand long-term extrapyramidal movement disorders, and possibly the effects of hyperprolactinemia, would become concerns of the past. Although the second-generation antipsychotics do generally cause less anticholinergic load and fewer extrapyramidal symptoms, they may have a propensity to cause hyperglycemia, hyperlipidemia, and weight gain. In addition, the landmark Clinical Antipsychotic Trials of Intervention Effectiveness (CATIE) study demonstrated that the efficacy of perphenazine (a firstgeneration antipsychotic) was comparable to that of many second-generation antipsychotics. ${ }^{24}$ The burden of adverse events was also comparable, although the actual frequency of specific adverse events differed among the antipsychotics evaluated. Since first-generation antipsychotics are less expensive than second-generation antipsychotics, this may provide clinicians with a reason to again consider prescribing firstgeneration antipsychotics, increasing the risk of hyperprolactinemia and its consequences.

The frequency of antipsychotic-induced hyperprolactinemia varies, depending on the antipsychotic agent prescribed. Although some of the second-generation antipsychotics, such as olanzapine, quetiapine, ziprasidone, aripiprazole, and clozapine, lack significant effects on prolactin, ${ }^{14}$ antipsychotic-induced hyperprolactinemia in patients who are treated with first-generation antipsychotics and risperidone is highly prevalent. ${ }^{12}$ The prevalence of hyperprolactinemia was evaluated in 402 patients taking firstgeneration antipsychotics or risperidone in average daily doses of $4.2-5.2 \mathrm{mg} .{ }^{12}$ This openlabel study found that $65.6 \%$ of women of reproductive age, $45.1 \%$ of postmenopausal women, and $42.4 \%$ of men experienced antipsychotic-induced hyperprolactinemia. Results from clinical trials of children and adolescents treated with risperidone showed an elevation of prolactin levels in $82-87 \%$ of patients compared with 3-7\% of those treated with placebo. ${ }^{22}$ Paliperidone caused elevations in prolactin levels that were comparable to those seen with risperidone, in both children and adults, which is not unexpected since paliperidone is the primary metabolite of risperidone. ${ }^{23}$ Although hyperprolactinemia is more likely to occur with first-generation antipsychotics and the second-generation agents risperidone and paliperidone, the extent of prolactin level increase shows great inter- and intraindividual variability (Table $1^{25-33}$ ). ${ }^{1}$ However, when patients are treated with higher doses of these agents, women (especially of reproductive age) and younger patients exhibit the greatest risk for hyperprolactinemia. ${ }^{4,12,34}$ 
Table 1. Studies That Measured Prolactin Levels in Patients Receiving Antipsychotic Drugs

Study Drugs (no. of patients)
Chlorpromazine, haloperidol,
trifluoperazine, fluphenazine
decanoate
(n=109; 67 male, 42 female) ${ }^{25}$

Flupenthixol decanoate,
haloperidol decanoate,
oral haloperidol, pimozide,
fluphenazine, sulpiride,
zuclopenthixol, droperidol,
chlorpromazine
(n=67; 47 male, 20 female $)^{26}$
Risperidone, olanzapine
(n=20; all female) ${ }^{27}$

Paliperidone

( $\mathrm{n}=374 ; 202$ male, 172 female), olanzapine

( $\mathrm{n}=128 ; 60$ male, 68 female), placebo

$(\mathrm{n}=126 ; 66 \text { male, } 60 \text { female })^{28}$

\section{Olanzapine}

( $\mathrm{n}=198 ; 170$ male, 28 female), haloperidol

( $\mathrm{n}=69 ; 62$ male, 7 female),

placebo

$(\mathrm{n}=68 ; 62 \text { male, } 6 \text { female })^{29}$

Olanzapine (7 female), clozapine (11 female), first-generation antipsychotics (31 female): flupenthixol $(n=12)$, perphenazine $(n=4)$, haloperidol $(n=5)$, perazine $(n=5)$, fluphenazine $(n=5)^{30}$

First-generation antipsychotics ( $\mathrm{n}=108 ; 72$ male, 36 female), olanzapine

( $\mathrm{n}=104 ; 65$ male, 39 female), risperidone

( $\mathrm{n}=58 ; 40$ male, 18 female); all switched to ziprasidone $e^{31}$

Study Description

Patients with schizophrenia were drug free for $\geq 8 \mathrm{wks}$, then treated with first-generation antipsychotics for up to $6 \mathrm{wks}$; number of patients receiving each drug not specified; mean doses were $653 \mathrm{mg} /$ day in men and $349 \mathrm{mg} /$ day in women ${ }^{\mathrm{a}}$

Patients with schizophrenia were treated for $\geq 2$ yrs with first-generation antipsychotics; number of patients receiving each drug not specified; women had to be premenopausal; mean \pm SD doses were $199.0 \pm 220.1$ $\mathrm{mg} /$ day in men and $384.4 \pm 302.5$ $\mathrm{mg} /$ day in women, ${ }^{\mathrm{a}} \mathrm{p}<0.05$

Patients with schizophrenia had menstrual disorders, galactorrhea, or sexual dysfunction; patients were receiving risperidone (mean \pm SD dose $3.5 \pm 1.2 \mathrm{mg}$ /day), then switched to olanzapine (mean \pm SD dose $9.1 \pm 1.8$ $\mathrm{mg} /$ day) for $8 \mathrm{wks}$

6-wk, multicenter, double-blind, randomized, placebo-controlled trial in patients with schizophrenia; previous therapy stopped for $\geq 3$ days; patients assigned to paliperidone $6 \mathrm{mg} /$ day $(\mathrm{n}=123), 9 \mathrm{mg} /$ day $(\mathrm{n}=122)$, or $12 \mathrm{mg} /$ day $(\mathrm{n}=129)$; olanzapine $10 \mathrm{mg} /$ day; or placebo

6-wk, double-blind, placebo-controlled study in patients with schizophrenia; patients assigned to olanzapine $5 \mathrm{mg}$ $(\mathrm{n}=65), 10 \mathrm{mg}(\mathrm{n}=64)$, or $15 \mathrm{mg}$ ( $\mathrm{n}=69)$; haloperidol $15 \mathrm{mg}$; or placebo; prolactin levels measured at baseline, and after 2, 4, and 6 wks of treatment

Patients with schizophrenia treated for $\geq 12$ wks with study drug, then prolactin levels measured; antipsychotic dosages not reported

Combined analysis of three open-label studies in patients with schizophrenia or schizoaffective disorder; at baseline, patients switched from unreported dosages of olanzapine, risperidone, or first-generation antipsychotics to ziprasidone; prolactin levels measured at baseline and after $6 \mathrm{wks}$ of ziprasidone, mean dose $91 \mathrm{mg} /$ day
Prolactin Effects

After 3 wks of therapy, mean \pm SD prolactin level was $39.65 \pm 27.91 \mathrm{ng} / \mathrm{ml}$ vs $8.29 \pm 5.1 \mathrm{ng} / \mathrm{ml}$ at baseline in men $(\mathrm{p}<0.05)$, and $102.54 \pm 66.03 \mathrm{ng} / \mathrm{ml}$ vs $10.74 \pm 8.1$ $\mathrm{ng} / \mathrm{ml}$ at baseline in women $(\mathrm{p}<0.05)$

Mean \pm SD prolactin level was $404 \pm 419.5$ $\mathrm{mIU} / \mathrm{L}$ in men vs $1061.3 \pm 629 \mathrm{mIU} / \mathrm{L}$ in women ( $\mathrm{p}<0.001) ; 16$ men $(34 \%)$ and 15 women $(75 \%)$ had levels above upper limit of normal (normal $<480 \mathrm{mIU} / \mathrm{L}$ )

Mean \pm SD prolactin level was 132.2 \pm 59.1 $\mathrm{ng} / \mathrm{ml}$ after $\geq 4 \mathrm{wks}$ of risperidone vs $23.4 \pm 22.7 \mathrm{ng} / \mathrm{ml}$ after $8 \mathrm{wks}$ of olanzapine $(\mathrm{p}<0.01)$

At 6 wks, mean \pm SD prolactin level in paliperidone group was $45.3 \pm 23.2 \mathrm{ng} / \mathrm{ml}$ vs $17.4 \pm 19.9 \mathrm{ng} / \mathrm{ml}$ at baseline in men, and $124.5 \pm 65.5 \mathrm{ng} / \mathrm{ml}$ vs $38.0 \mathrm{ng} / \mathrm{ml}$ at baseline in women; mean prolactin level decreased from baseline in those receiving olanzapine or placebo (no statistical analyses were reported)

Actual prolactin levels not reported; however, at 2, 4, and 6 wks, levels were above normal in both men and women receiving haloperidol $(\mathrm{p}<0.001)$, whereas olanzapine caused slight increase above normal only in women; prolactin level did not increase with placebo at any time point

Mean \pm SD prolactin levels were $654 \pm 456$ $\mathrm{mE} / \mathrm{L}$ in olanzapine group ( $\mathrm{p}=0.005 \mathrm{vs}$ first-generation antipsychotic group), $467 \pm 170 \mathrm{mE} / \mathrm{L}$ in clozapine group $(\mathrm{p}<0.001$ vs first-generation antipsychotic group), and $1600 \pm 1278 \mathrm{mE} / \mathrm{L}$ in firstgeneration antipsychotic group (normal range $70-410 \mathrm{mE} / \mathrm{L}$ )

After 6 wks of ziprasidone, mean \pm SD prolactin levels decreased in the firstgeneration antipsychotic group $(27.4 \pm 28.1 \mathrm{ng} / \mathrm{ml}, \mathrm{p}<0.05)$ and in the risperidone group $(51.0 \pm 41.07 \mathrm{ng} / \mathrm{ml}$, $\mathrm{p}<0.0001)$; prolactin level did not change in the olanzapine group $(15.2 \pm 11.3 \mathrm{ng} / \mathrm{ml})$

\section{Consequences}

Antipsychotic agents are used for both United States Food and Drug Administration (FDA)- approved and nonapproved indications in both adults and children, including schizophrenia, bipolar disorder, schizoaffective disease, the 
Table 1. Studies That Measured Prolactin Levels in Patients Receiving Antipsychotic Drugs (continued)

\begin{tabular}{|c|c|c|}
\hline Study Drugs (no. of patients) & Study Description & Prolactin Effects \\
\hline $\begin{array}{l}\text { Quetiapine }(n=28) \\
\text { haloperidol }(n=24) \\
\text { placebo }(n=19)^{32}\end{array}$ & $\begin{array}{l}\text { 6-wk, randomized, double-blind, } \\
\text { placebo-controlled study in patients } \\
\text { with schizophrenia; patients assigned } \\
\text { to quetiapine } 750 \mathrm{mg} / \text { day, haloperidol } \\
12 \mathrm{mg} / \text { day, or placebo; prolactin levels } \\
\text { measured after } 6 \text { wks of treatment; sex } \\
\text { distribution of patients not reported }\end{array}$ & $\begin{array}{l}\text { After } 6 \text { wks of therapy, mean prolactin levels } \\
\text { were } 13.9 \mathrm{ng} / \mathrm{ml} \text { in the quetiapine group } \\
\text { (p=NS vs placebo), } 28.8 \mathrm{ng} / \mathrm{ml} \text { in the } \\
\text { haloperidol group (p=0.0075 vs placebo), } \\
\text { and } 14.7 \mathrm{ng} / \mathrm{ml} \text { in the placebo group }\end{array}$ \\
\hline $\begin{array}{l}\text { Aripiprazole } \\
\text { ( } \mathrm{n}=204 ; 146 \text { male, } 58 \text { female }) \\
\text { haloperidol } \\
(\mathrm{n}=104 ; 68 \text { male, } 36 \text { female }) \\
\text { placebo } \\
(\mathrm{n}=106 ; 74 \text { male, } 32 \text { female })^{33}\end{array}$ & $\begin{array}{l}\text { 4-wk, randomized, double-blind, } \\
\text { placebo-controlled study in patients } \\
\text { with schizophrenia; patients were } \\
\text { weaned from previous antipsychotic } \\
\text { and assigned to aripiprazole } 15 \mathrm{mg} \\
(\mathrm{n}=102) \text { or } 30 \mathrm{mg}(\mathrm{n}=102), \text { haloperidol } \\
10 \mathrm{mg} \text {, or placebo; prolactin levels } \\
\text { measured at baseline and at last } \\
\text { study visit }\end{array}$ & $\begin{array}{l}\text { Mean prolactin levels in both aripiprazole } \\
\text { groups decreased slightly from baseline } \\
\text { (15-mg dose: } 12.4 \mathrm{ng} / \mathrm{ml} \text {; } 30-\mathrm{mg} \text { dose: } \\
12.3 \mathrm{ng} / \mathrm{ml} \text {; } \mathrm{p}=\mathrm{NS} \text { vs placebo); mean } \\
\text { prolactin level in haloperidol group } \\
\text { increased from a baseline of } 15.7 \mathrm{ng} / \mathrm{ml} \\
\text { to } 38.2 \mathrm{ng} / \mathrm{ml} \text { ( } \mathrm{p}<0.001 \mathrm{vs} \text { placebo), } \\
\text { no significant change in mean prolactin } \\
\text { level in placebo group ( } 11.2 \mathrm{ng} / \mathrm{ml})\end{array}$ \\
\hline
\end{tabular}

$\mathrm{NS}=$ not significant

${ }^{a}$ Doses were expressed as chlorpromazine equivalents.

behavioral symptoms of dementia, treatmentresistant depression, personality disorders, and autism. With increased utilization, more patients, including very young patients, are at risk for developing hyperprolactinemia and its resulting effects. Since the 1990s, children as young as 2 years have been exposed to antipsychotic drugs at rates similar to that of adults, and utilization has continued to increase in this demographic, especially with second-generation antipsychotics. ${ }^{35,36}$ Long-term consequences of using antipsychotic agents in this population, including hyperprolactinemia, are unknown.

\section{Menstrual Disturbances}

One of the effects that appears most directly related to hyperprolactinemia is menstrual disturbance. A study of Indian women taking first-generation antipsychotics found that the frequency of menstrual disturbance was 54\%, amenorrhea $12 \%$, and galactorrhea $32 \% .{ }^{37}$ The presence of galactorrhea was more likely in those who had previously given birth. Other studies have compared menstrual disturbances between those taking first-generation and those taking second-generation antipsychotics. In one study, abnormal menstrual cycles were reported in 88\% of women treated with risperidone compared with $48 \%$ of women taking first-generation antipsychotics. ${ }^{12}$ In an 8-week comparison of risperidone and olanzapine, $60 \%$ of females taking risperidone and $25 \%$ of those taking olanzapine reported amenorrhea at 8 weeks. ${ }^{27}$ An outpatient multicenter study based in Europe calculated the odds ratio for amenorrhea and galactorrhea when comparing a variety of antipsychotics with olanzapine. ${ }^{38}$ The odds ratio for amenorrhea with risperidone was 2.49 , quetiapine 0.75 , clozapine 1.56 , and oral firstgeneration antipsychotics 1.06. Another multicenter study, conducted in Spain, found that the percentage of women experiencing amenorrhea in those taking haloperidol was $14 \%$, olanzapine $11 \%$, quetiapine $5.6 \%$, and risperidone $28.2 \%{ }^{39}$ Based on the overall results of these studies, although the specific percentages vary, the risk of developing menstrual disturbances secondary to an antipsychotic appears to roughly parallel the risk of developing hyperprolactinemia.

\section{Sexual Dysfunction}

Another consequence of hyperprolactinemia is sexual dysfunction. However, evaluating effects on sexual functioning is a rather difficult task because so many different factors other than pharmacology can affect sexual functioning. Some data indicate that before any treatment with antipsychotics, men with schizophrenia are less likely to form sexual relationships than men without schizophrenia. ${ }^{40}$ The reported frequency of sexual dysfunction depends strongly on the study methodology, and when no specific effort is made to collect information regarding sexual functioning, the rate of reported dysfunction is universally low. In one study, only $10 \%$ of patients spontaneously reported experiencing sexual dysfunction. However, when specifically surveyed, this complication was reported in up to 
$60 \%$ of patients treated with first-generation antipsychotics and risperidone, and frequencies of reported difficulties with orgasm and libido were similar for women and men. ${ }^{41}$ Although it is clear that hyperprolactinemia can cause sexual dysfunction, it is certainly not the only possible cause in many patients who are taking antipsychotics. Other pharmacologic effects of many antipsychotics, such as $\alpha$-blockade or agonist or antagonist effects on serotonin receptors, may also affect sexual functioning. Consequently, the rates of sexual dysfunction (loss of libido, orgasmic difficulties, and erectile dysfunction) are less likely to be correlated directly with prolactin levels. One study found that the odds ratio (compared with olanzapine) for loss of libido was 1.46 with risperidone, 1.11 with quetiapine, 1.27 with clozapine, and 1.73 with oral first-generation antipsychotics. ${ }^{38}$ In patients who had taken a specific antipsychotic for a 6month period, another study found that the percentage of decreased sexual desire in men and women taking haloperidol was $27.8 \%$, olanzapine $36.5 \%$, quetiapine $14.3 \%$, and risperidone $38.8 \%{ }^{39}$

\section{Bone Mineral Density}

Patients receiving long-term antipsychotic treatment causing elevations of prolactin levels are at an increased risk for developing osteopenia and osteoporosis, although many other factors can affect BMD. Of interest, estrogen levels in women do not always coincide with prolactin levels. One group of authors obtained 17- $\beta$ estradiol plasma levels in 75 women with schizophrenia. ${ }^{30}$ Although prolactin levels were significantly higher in the group taking oral firstgeneration antipsychotics than in those taking either clozapine or olanzapine, the 17- $\beta$ estradiol levels were significantly lower in the olanzapine group than in the clozapine and oral firstgeneration antipsychotics groups. Overall, 57.3\% of the patients exhibited hypoestrogenism $(<30$ $\mathrm{pg} / \mathrm{ml}$ in follicular phase or $<100 \mathrm{pg} / \mathrm{ml}$ in the periovulatory phase), which did not always correlate with hyperprolactinemia.

Some researchers have hypothesized that schizophrenia may be associated with hypoestrogenemia in women, regardless of drug treatment. ${ }^{42,43}$ In a study that evaluated 402 patients with schizophrenia treated with firstgeneration antipsychotics or risperidone, $23.2 \%$ of women and $31 \%$ of men had osteopenia ( $\mathrm{T}$ score $\leq-1)$, and prolactin level elevation was a significant risk factor only in men. ${ }^{44}$ The authors concluded that decreased BMD is highly prevalent in this population. Moreover, in a study of 55 patients with schizophrenia who were treated with prolactin-elevating antipsychotics for at least 10 years, the authors found reduced BMD in $57 \%$ of men and $32 \%$ of postmenopausal women. ${ }^{45}$ Using a primary care dataset in the United Kingdom, a group of authors conducted a case-control study identifying all patients who had a fractured neck of the femur (or hip fracture)." 46 Each case was matched with two control subjects for age, sex, and type of general practice, for the risk of hip fracture. Their study identified an association between hip fracture and use of prolactin-elevating antipsychotic drugs (odd ratio $2.6,95 \%$ confidence interval 2.43-2.78). These studies indicate that hyperprolactinemia secondary to antipsychotic treatment affects BMD in patients with schizophrenia, but that decreased BMD may also occur in the absence of elevated prolactin levels.

\section{Breast and Pituitary Tumors}

Some literature suggests a possible link between prolactin level and breast cancer. Three hundred six postmenopausal women with breast cancer were compared with postmenopausal control subjects on the basis of age, postmenopausal hormone use, and timing and method of blood collection, by using a nested case-control study design. ${ }^{47}$ In this study, postmenopausal women with higher prolactin levels were at an increased risk for breast cancer after other risk factors for breast cancer were controlled. More specifically, women who had prolactin levels in the upper quartile had twice the risk for breast cancer compared with women in the bottom quartile. Furthermore, findings from a recently published review, citing seven prospective studies, supports the link between prolactin and an increased risk of breast cancer in both pre- and postmenopausal women. ${ }^{48}$ Relating this to patients with psychiatric disorders, a retrospective cohort study was conducted with use of the Medicaid and Pharmaceutical Assistance to the Aged and Disabled databases in New Jersey that contained 52,819 women who were exposed and 55,289 women who were not exposed to dopamine antagonists. ${ }^{49}$ The authors found a $16 \%$ increase in the risk of breast cancer in patients exposed to antipsychotic dopamine antagonists. Although the potential role of confounding factors was 
cited as a limitation by the authors, they did find a dose-response relationship indicating a higher risk of breast cancer with increased dosages of these drugs. In a medical record review, another group found that the frequency of breast cancer among 275 women older than 40 years who had psychiatric disorders was 9.5 times higher than the frequency reported in the general population. ${ }^{50}$

A possible connection between elevated prolactin levels and pituitary tumors has been suggested by a recent pharmacovigilance study. ${ }^{51}$ Data from the FDA MedWatch program was evaluated by using a Bayesian model to calculate an adjusted reported ratio for pituitary tumor risk. Risperidone was associated with the highest adjusted reported ratio (18.7), but values were also elevated for haloperidol (5.6), ziprasidone (3.0), and olanzapine (2.3). The authors concluded that their results do not necessarily indicate a cause-and-effect relationship, but their findings and the results from animal studies, which found that hyperprolactinemia is associated with pituitary tumors in rodents, suggest that the relationship between elevated prolactin levels and pituitary tumors deserves further investigation.

Larger studies are needed to validate the possible connections between hyperprolactinemia and breast and/or pituitary tumors, since many risk factors, aside from hyperprolactinemia, play a role in the etiology of these cancers.

\section{Antipsychotic Drug Selection and Management of the Effects of Hyperprolactinemia}

Many different factors are considered in the choice of an antipsychotic for a specific patient. The major factor is whether the agent will effectively treat the psychosis in that individual patient. Unfortunately, there is no way of determining a priori which drug will work in a specific individual. Given this caveat, most clinicians will select the antipsychotic that they believe will be associated with the fewest unacceptable adverse effects. Sometimes the major issue will be weight gain or glucose intolerance and other times it may be issues associated with hyperprolactinemia such as sexual dysfunction or menstrual disturbances.

If a major goal is to prevent antipsychoticinduced hyperprolactinemia, appropriate drug selection is key. The relative risk of antipsychotics to cause elevated prolactin levels, based on an extrapolation of available data, in approximate order of highest to lowest propensity for causing hyperprolactinemia is as follows: first-generation antipsychotics, risperidone, paliperidone > ziprasidone $>$ olanzapine $>$ quetiapine, clozapine $>$ aripiprazole. In addition, if prescribing a highly potent $\mathrm{D}_{2}$-receptor-blocking agent, using the lowest effective dose will help minimize the risk of developing hyperprolactinemia. ${ }^{34}$ When hyperprolactinemia causes significant effects, possible options are changing to a prolactinsparing antipsychotic or reducing the dose. ${ }^{34}$ However, relapse is a risk with both of these alternatives. ${ }^{1,13,52}$ An additional therapeutic option is to add an antipsychotic that may normalize prolactin levels, such as aripiprazole, to the drug regimen. ${ }^{53}$ Subsequent to positive anecdotal reports, a randomized, double-blind, placebo-controlled study was conducted of adjunctive treatment with aripiprazole added to treatment of 54 patients with schizophrenia who were stabilized with haloperidol 20-25 mg/day. ${ }^{54}$ Of the 26 patients receiving an aripiprazole dose of $15 \mathrm{mg}$ /day (increased to $30 \mathrm{mg} /$ day after 4 wks), prolactin levels normalized in $84.6 \%$ of the aripiprazole group (group by time interaction, $\mathrm{p}<0.0001$ ) and in only $3.6 \%$ of the placebo group after 8 weeks. Prolactin-related adverse effects also were significantly decreased in the group receiving aripiprazole.

When it is necessary to use an antipsychotic agent that is likely to cause hyperprolactinemia, appropriate monitoring and management is paramount. Specifically, clinicians should inquire about menstrual disturbances in women, changes in libido or galactorrhea in men and women, and erectile or ejaculatory dysfunction in men. ${ }^{52}$ If these symptoms are present, it would be reasonable to obtain a baseline prolactin level. After several weeks of antipsychotic treatment, a follow-up prolactin level could be drawn for comparison, at the same time and in the same state (fasted or fed) as the baseline level. ${ }^{13}$

If an adverse effect that is distressing to the patient is directly related to elevated prolactin levels (such as amenorrhea or galactorrhea) and cannot be managed by discontinuing the offending antipsychotic, then treatment with a dopamine agonist such as bromocriptine or cabergoline could be considered. Cabergoline has a longer elimination half-life and requires only once- or twice-weekly administration, in contrast to bromocriptine, which requires multiple daily doses (unless slow-release formulations are used). In some cases, cabergoline has caused less 
orthostatic hypotension, dizziness, headache, and nasal congestion than bromocriptine. ${ }^{55}$ In patients with psychiatric disorders, there is also a risk for worsening of psychiatric symptoms when a dopamine agonist is added to the drug regimen. In women, combined oral contraceptives can be used to resume menses and correct hypoestrogenism. ${ }^{18,56}$ In general, amenorrhea responds better to treatment strategies than does galactorrhea. ${ }^{1}$

If decreased libido, orgasmic difficulties, or erectile dysfunction are suspected to be related to an elevated prolactin level, then a corrective measure should be started. In addition to the effect that sexual dysfunction can have on a patient's quality of life, it is also likely to negatively affect adherence to antipsychotic therapy. ${ }^{57,58}$ In general, patients should be informed that antipsychotic drugs can be associated with sexual dysfunction because patients may be reluctant to discuss embarrassing adverse effects, especially if they do not realize that these may be drug induced. To help circumvent this, counseling patients on potential adverse effects is important, and clinicians should regularly inquire whether the patient is experiencing any untoward effects. ${ }^{13,34,52}$ Clinicians should also acknowledge that other factors can increase the risk of sexual dysfunction in patients with schizophrenia. Some of these may include the social impact of schizophrenia, as well as positive, negative, affective, and cognitive symptoms. ${ }^{1,41}$ If sexual dysfunction is due to hyperprolactinemia, switching to a prolactin-sparing antipsychotic will alleviate the situation. In cases where this is not possible, a dopamine agonist (bromocriptine or cabergoline) might be added to the drug regimen.

Patients with schizophrenia are at risk for reduced BMD secondary to schizophrenia itself and drug-related factors. ${ }^{59-61}$ Factors unrelated to antipsychotic treatment that put patients with schizophrenia at risk for decreased BMD include smoking, polydipsia resulting in excessive calcium excretion, decreased exposure to sunlight, excessive alcohol consumption, increased age, poor nutrition, and inadequate exercise, and possibly, the disease itself. ${ }^{56,60}$ Obtaining baseline BMD studies is recommended in all patients with schizophrenia, as is monitoring prolactin levels in patients treated with antipsychotic drugs when early effects, such as decreased libido or amenorrhea, appear. ${ }^{60}$ Repeat testing of prolactin level in 3 months can be useful to monitor for sustained elevation of prolactin. ${ }^{60}$

Likewise, BMD screening is recommended in older men with schizophrenia who have been treated with long-term first-generation antipsychotic therapy. ${ }^{16,61}$ Although there is a paucity of data surrounding who is at greatest risk for developing osteoporosis and osteopenia, some recommend providing education to patients with schizophrenia to reduce their risk. Education could include information on the importance of a well-balanced diet with appropriate intake of calcium and vitamin D, weight-bearing exercise, smoking cessation, limiting caffeine and alcohol intake, and ensuring adequate exposure to sunlight. ${ }^{18,46,56}$ In addition to monitoring BMD, bisphosphonates may be used as a preventive measure in patients at high risk for osteoporosis.

In summary, if changing the drug dosage or antipsychotic agent is not feasible, dopamine agonists may be considered, especially in cases of amenorrhea or galactorrhea. However, use of these agents is somewhat controversial due to the risk of worsening the patient's psychiatric symptoms. ${ }^{1,11}$ Combined oral contraceptives may also be considered in women with prolonged amenorrhea who are at risk for developing osteoporosis. ${ }^{1}$ It should be remembered that use of oral contraceptives is not entirely benign and may increase the risk of developing breast cancer, as well as other conditions.

\section{Conclusion}

Both clinicians and patients must be aware of the risk of antipsychotic-induced hyperprolactinemia and its potential clinical implications. Health care professionals should provide appropriate education and vigilant monitoring of this druginduced complication. Hyperprolactinemia has seriously devastating short-and long-term consequences that can dramatically affect the lives of patients who are treated with antipsychotic drugs. Although first-generation antipsychotics are most recognized for causing hyperprolactinemia, clinicians must be aware that patients who are treated with second-generation antipsychotics remain at risk, especially those receiving risperidone or paliperidone. Moreover, monitoring for hyperprolactinemia should be standardized among clinicians. Additional research, however, is needed to determine the long-term effects of antipsychotic-induced hyperprolactinemia, as growing numbers of children and adults are being treated with these drugs. 


\section{References}

1. Haddad PM, Wieck A. Antipsychotic-induced hyperprolactinemia: mechanisms, clinical features, and management. Drugs 2004;64:2291-314.

2. Ben-Jonathan N, Hugo ER, Brandebourg TD, LaPensee CR. Focus on prolactin as a metabolic hormone. Trends Endocrinol Metab 2006;17:110-16.

3. Harris J, Stanford PM, Oakes SR, Ormandy CJ. Prolactin and prolactin receptor: new targets of an old hormone. Ann Med 2004;36:414-25.

4. Parker KL, Schimmer BP. Pituitary hormones and their hypothalamic releasing hormones. In: Brunton LL, Lazo JS, Parker KL, eds. Goodman \& Gilman's the pharmacologic basis of therapeutics, 1lth ed. New York: McGraw-Hill Companies, Inc., 2006:1489-510.

5. Young RM, Lawford BR, Barnes M, et al. Prolactin levels in antipsychotic treatment of patients with schizophrenia carrying the DRD $2 * A 1$ allele. Br J Psychiatry 2004;185:147-51.

6. Thompson J, Thomas N, Singleton A, et al. $\mathrm{D}_{2}$ dopamine receptor gene (DRD2) Taql A polymorphism: reduced dopamine $D_{2}$ receptor binding in the human striatum associated with the Al allele. Pharmacogenetics 1997;7:479-84.

7. Nordström AL, Farde L. Plasma prolactin and central $D_{2}$ receptor occupancy in antipsychotic drug-treated patients. J Clin Psychopharmacol 1998;18:305-10.

8. Mihara K, Kondo T, Suzuki A, et al. Prolactin response to nemonapride, a selective antagonist for $\mathrm{D}_{2}$, like dopamine receptors, in schizophrenic patients in relation to Taql A polymorphism of DRD2 gene. Psychopharmacology 2000;149: 246-50.

9. Molitch ME. Medication-induced hyperprolactinemia. Mayo Clin Proc 2005;80:1050-7.

10. Melmed S, Jameson JL. Disorders of the anterior pituitary and hypothalamus. In: Kasper DL, Fauci AS, Longo DL, Braunwald E, Hauser SL, Jameson JL, eds. Harrison's principles of internal medicine, 16th ed. New York: McGraw-Hill Companies, Inc., 2005:2076-97.

11. Byerly M, Suppes T, Tran Q, Baker RA. Clinical implications of antipsychotic-induced hyperprolactinemia in patients with schizophrenia spectrum or bipolar spectrum disorders: recent developments and current perspectives. J Clin Psychopharmacol 2007;27:639-61.

12. Kinon BJ, Gilmore JA, Liu H, Halbreich UM. Prevalence of hyperprolactinemia in schizophrenic patients treated with conventional antipsychotic medications or risperidone. Psychoneuroendocrinology 2003;28:55-68.

13. Maguire GA. Prolactin elevation with antipsychotic medications: mechanisms of action and clinical consequences. J Clin Psychiatry 2002;63(suppl 4):56-62.

14. Crismon ML, Buckley PF. Schizophrenia. In: DiPiro JT, Talbert RL, Yee GC, Matzke GR, Wells BG, Posey LM, eds. Pharmacotherapy a pathophysiologic approach, 6th ed. New York: McGraw-Hill Companies, Inc., 2005;1209-33.

15. Halbreich U, Kinon BJ, Gilmore JA, Kahn LS. Elevated prolactin levels in patients with schizophrenia: mechanisms and related adverse events. Psychoneuroendocrinology 2003;28:53-67.

16. Meyer JM, Lehman D. Bone mineral density in male schizophrenia patients: a review. Ann Clin Psychiatry 2006;18:43-8.

17. Hummer M, Malik P, Gasser RW, et al. Osteoporosis in patients with schizophrenia. Am J Psychiatry 2005;162:162-7.

18. Meaney AM, O'Keane V. Bone mineral density changes over a year in young females with schizophrenia: relationship to medication and endocrine variables. Schizophr Res 2007;93:136-43.

19. Welsch CW, Nagasawa H. Prolactin and murine mammary tumorigenesis: a review. Cancer Res 1977;37:951-63.

20. Palmer J, Maurer LH. Prolactin and breast cancer [letter]. Lancet 1972;2:1036.

21. Minton JP. Prolactin and human breast cancer. Am J Surg 1974;128:628-30.
22. Janssen Pharmaceutica Products, LP. Risperdal (risperidone) package insert. Titusville, NJ; 2007.

23. Knegtering R, Baselmans P, Castelein S, Bosker F, Bruggeman $\mathrm{R}$, van den Bosch RJ. Predominate role of the 9-hydroxy metabolite of risperidone in elevating blood prolactin levels. Am J Psychiatry 2005;162:1010-12.

24. Rosenheck RA, Leslie DL, Sindelar J, et al, for the CATIE Study Investigators. Cost-effectiveness of second-generation antipsychotics and perphenazine in a randomized trial of treatment for chronic schizophrenia. Am J Psychiatry 2006;163: 2080-9.

25. Kuruvilla A, Peedicayil J, Srikrishna G, Kuruvilla K, Kanagasabapathy AS. A study of serum prolactin levels in schizophrenia: comparison of males and females. Clin Exp Pharm Physiol 1992;19:603-6.

26. Smith S, Wheeler MJ, Murray R, O'Keane V. The effects of antipsychotic-induced hyperprolactinaemia on the hypothalamicpituitary-gonadal axis. J Clin Psychopharmacol 2002;22:109-14.

27. Kim KS, Pae CU, Chae JH, et al. Effects of olanzapine on prolactin levels of female patients with schizophrenia treated with risperidone. J Clin Psychiatry 2002;63:408-13.

28. Kane J, Canas F, Kramer M, et al. Treatment of schizophrenia with paliperidone extended-release tablets: a 6-week placebocontrolled trial. Schizophr Res 2007;90:147-61.

29. Crawford AMK, Beasley CM, Tollefson GD. The acute and long-term effect of olanzapine compared with placebo and haloperidol on serum prolactin concentrations. Schizophr Res 1997;26:41-54.

30. Bergemann N, Mundt C, Parzer P, et al. Plasma concentrations of estradiol in women suffering from schizophrenia treated with conventional versus atypical antipsychotics. Schizophr Res 2005;73:357-66.

31. Weiden PJ, Daniel DG, Simpson G, Romano SJ. Improvement in indices of health status in outpatients with schizophrenia switched to ziprasidone. J Clin Psychopharmacol 2003;23: 595-600.

32. Arvanitis LA, Miller BG, for the Seroquel Trial 13 Study Group. Multiple fixed doses of "Seroquel" (quetiapine) in patients with acute exacerbation of schizophrenia: a comparison with haloperidol and placebo. Biol Psychiatry 1997;42:233-46.

33. Kane JM, Carson WH, Saha AR, et al. Efficacy and safety of aripiprazole and haloperidol versus placebo in patients with schizophrenia and schizoaffective disorder. J Clin Psychiatry 2002;63:763-71.

34. Haddad PM, Sharma SG. Adverse effects of atypical antipsychotics differential risk and clinical implications. CNS Drugs 2007;21:911-36.

35. Zito JM, Safer DJ, dosReis S, et al. Psychotropic practice patterns for youth: a 10-year perspective. Arch Pediatr Adolesc Med 2003;157:17-25.

36. Zito JM, Safer DJ, Valluri S, Gardner JF, Korelitz JJ, Mattison DR. Psychotherapeutic medication prevalence in Medicaidinsured preschoolers. J Child Adolesc Psychopharmacol 2007;17:195-203.

37. Thangavelu K, Geetanjali S. Menstrual disturbance and galactorrhea in people taking conventional antipsychotic medications. Exper Clin Psychopharmacol 2006;14:459-60.

38. Lambert M, Haro JM, Novick D, et al. Olanzapine vs. other antipsychotics in actual out-patient settings: six months tolerability results from the European schizophrenia out-patient health outcomes study. Acta Psychiatr Scand 2005;111:232-43.

39. Bobes J, García-Portilla MP, Rejas J, et al. Frequency of sexual dysfunction and other reproductive side-effects in patients with schizophrenia treated with risperidone, olanzapine, quetiapine, or haloperidol: the results of the EIRE study. J Sex Marital Ther 2003;29:125-47.

40. Kelly DL, Conley RR. Sexuality and schizophrenia: a review. Schizophr Bull 2004;30:767-79.

41. Knegtering H, van der Moolen AE, Castelein S, Kluiter H, van den Bosch RJ. What are the effects of antipsychotics on sexual dysfunctions and endocrine functioning? Psychoneuroendocrinology 2003;28(suppl 2):109-23. 
42. Riecher-Rossler A. Oestrogens and schizophrenia. Curr Opin Psychiatry 2003;16:187-92.

43. Huber TJ, Rollnik J, Wilhelms J, von zur Mühlen A, Emrich HM, Schneider U. Estradiol levels in psychotic disorders. Psychoneuroendocrinology 2001;26;27-35.

44. Liu-Seifert H, Kinon BJ, Ahl J, Lamberson S. Osteopenia associated with increased prolactin and aging in psychiatric patients treated with prolactin-elevating antipsychotics. Ann N Y Acad Sci 2004;1032:297-8.

45. Meaney AM, Smith S, Howes OD, O'Brien M, Murray RM, O'Keane V. Effects of long-term prolactin-raising antipsychotic medication on bone mineral density in patients with schizophrenia. Br J Psychiatry 2004;184:503-8.

46. Howard L, Kirkwood G, Leese M. Risk of hip fracture in patients with a history of schizophrenia. Br J Psychiatry 2007;190:129-34

47. Hankinson SE, Willett WC, Michaud DS, et al. Plasma prolactin levels and subsequent risk of breast cancer in postmenopausal women. J Natl Cancer Inst 1999;91:629-34.

48. Tworoger SS, Hankinson SE. Prolactin and breast cancer risk. Cancer Lett 2006;243:160-9.

49. Wang PS, Walker AM, Tsuang MT, et al. Dopamine antagonists and the development of breast cancer. Arch Gen Psychiatry 2002;59:1147-54.

50. Halbreich U, Shen J, Panaro V. Are chronic psychiatric patients at increased risk for developing breast cancer? Am J Psychiatry 1996;153:559-60.

51. Szarfman A, Tonning JM, Levine JG, Doraiswamy PM. Atypical antipsychotics and pituitary tumors: a pharmaco- vigilance study. Pharmacotherapy 2006;26:748-58.

52. Marder SR, Essock SM, Miller AL, et al. Physical health monitoring of patients with schizophrenia. Am J Psychiatry 2004;161:1334-49.

53. Wolf J, Fiedler U. Hyperprolactinemia and amenorrhea associated with olanzapine normalized after addition of aripiprazole. J Clin Pharm Ther 2007;32:197-8.

54. Shim JC, Shin JG, Kelly DL, et al. Adjunctive treatment with a dopamine partial agonist, aripiprazole, for antipsychoticinduced hyperprolactinemia: a placebo-controlled trial. Am J Psychiatry 2007;164:1404-10.

55. Bankowski BJ, Zacur HA. Dopamine agonist therapy for hyperprolactinemia. Clin Obstet Gynecol 2003;46:349-62.

56. Naidoo U, Goff DC, Klibanski A. Hyperprolactinemia and bone mineral density: the potential impact of antipsychotic agents. Psychoneuroendocrinology 2003;28:97-108.

57. Perkins DO. Predictors of noncompliance in patients with schizophrenia. J Clin Psychiatry 2002;63:1121-8.

58. Fleischhacker WW, Meise U, Gunther V, Kurz M. Compliance with antipsychotic drug treatment: influence of side effects. Acta Psychiatrica Scand 1994; 89(suppl 382):11-15

59. Halbreich U. Osteoporosis, schizophrenia and antipsychotics: the need for a comprehensive multifactorial evaluation. CNS Drugs 2007;21:641-57.

60. Misra M, Papakostas GI, Klibanski A. Effects of psychiatric disorders and psychotropic medications on prolactin and bone metabolism. J Clin Psychiatry 2004:65:1607-18

61. Lehman D, Meyer JM. Decreased bone mineral density in male schizophrenia patients. Schizophr Res 2005;76:131-3. 